\title{
Design and Fabrication of Information Security Films with Microlouver Pattern and ZnO Nano-Ink Filling
}

\author{
Gwan Hyeon Kim, So Won Kim, Seong Eui Lee, and Hee Chul Lee $\mathbb{B D}^{\dagger}$ \\ Department of Advanced Materials Engineering, Korea Polytechnic University, Siheung 15073, Korea \\ (Received May 7, 2019; Revised July 8, 2019; Accepted July 9, 2019)
}

\begin{abstract}
Information security films that can ensure personal privacy by reducing the viewing angle of display screens were fabricated by microlouver patterning and a $\mathrm{ZnO}$ nano-ink filling process. Optical simulation results demonstrated that all the microlouver films showed good security performances. Security performances were evaluated as calculated relative luminance ratios compared between the side and front. Based on the simulation results, microlouver films were fabricated by UV imprint lithography and nano-ink bar coating. However, distortion of the microlouver pattern occurred with the use of high-viscosity nano-inks such as $\mathrm{ZrO}_{2}$ and $\mathrm{TiO}_{2}$, and the $\mathrm{CuO}$-filled microlouver film suffered from very low optical transmittance. Accordingly, the effects of $\mathrm{ZnO}$ filling height on security performance were intensively investigated through simulation and experimental measurements. The fabricated microlouver film with a $75-\mu \mathrm{m}$-high $\mathrm{ZnO}$ filling exhibited a good relative luminance ratio of 0.75 at a $60^{\circ}$ side angle and a transmittance of $44 \%$ at a wavelength of $550 \mathrm{~nm}$.
\end{abstract}

Key words : Information security film, Microlouver pattern, Viewing angle, ZnO nano-ink

\section{Introduction}

$\mathrm{T}$ he use of personal portable devices is rapidly growing in everyday life, and there is a risk of important personal information being exposed to people nearby through display screens. For example, personal information can be leaked when messages or e-mails are displayed on personal portable devices when they are being used on public transportation. Therefore, attaching information security films to the displays of mobile phones or laptops is becoming increasingly common. ${ }^{1,2)}$

Most information security films use microlouver film technology. In microlouvers, patterns with high aspect ratios are precisely arranged and inter-pattern spaces are filled with shadowing materials in order to decrease the screen viewing angle by allowing for viewing from the front while blocking views from the sides. An important parameter in the fabrication of microlouver films is aspect ratio, which is the ratio of pattern height to width, as it is important for determining film security performance. Existing microlouver films are fabricated by repeatedly bonding several layers of transparent and shadowing films and cutting them vertically. This method, however, makes the films expensive because it involves numerous processes and long production times. ${ }^{3,4)}$ Moreover, common shadowing materials such as

\footnotetext{
Corresponding author: Hee Chul Lee

E-mail : eechul@kpu.ac.kr

Tel : +82-31-8041-0589 Fax : +82-31-8041-0599

ORCID

https://orcid.org/0000-0002-2280-8647
}

black carbon that are used to fill the microlouver pattern and improve its opacity to block side viewing can also significantly decrease optical transmittance from the front.

This study aims to develop a few-step process for fabricating high-quality information security films filled with shadowing materials suitable for microlouver patterns using nanoimprinting and nano-inking. ${ }^{5,6)}$ The following research process was conducted to fabricate microlouver films with excellent security characteristics through a controlled viewing angle. First, film security characteristics were investigated according to shadowing material type for filling an isosceles trapezoidal pattern using an optical simulation method, and the results were verified through experiments. Next, optical simulations were performed to investigate the effects of filling height of the optimized shadowing material in the microlouver pattern. Finally, microlouver pattern films with high-refractive-index shadowing materials were fabricated using nanoimprint patterning and nano-inking, and their optical characteristics were evaluated. The results were also compared with the simulated values.

\section{Experimental Procedure}

Before conducting experiments, computer simulations were performed using optical simulation software (Optisworks, OPTIS KOREA) to predict film optical characteristics according to filler shadowing material and filling height. The Optisworks software can predict the optical characteristics of a structure modeled through Solidworks (Dassault Systems Korea) by deriving light paths. Table 1 shows the simulation conditions and sizes of the patterns 
Table 1. Detailed Optical Simulation Conditions

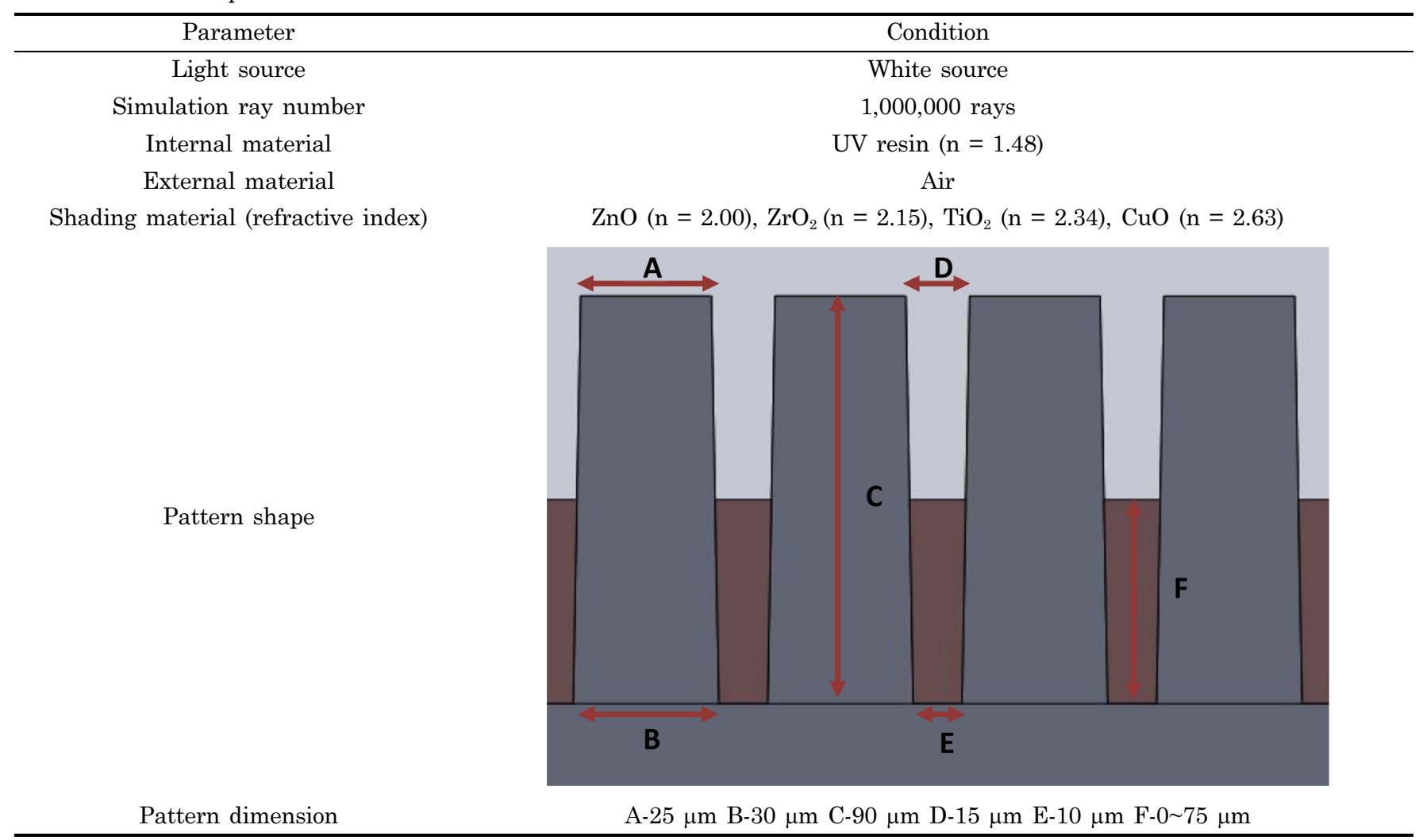

used in this study. Simulation were performed to investigate the distributions of light from the front irradiated from back side after passing through the structure and security characteristics according to shadowing material and nanoink height. The microlouver films used in experiments were fabricated in the following sequence through the silicon stamp mold and nanoimprint process. ${ }^{5,6)}$ A UV-curable resin (ND-938-6, refractive index $n=1.48$, NP Chemical, Korea) was applied to a polyethylene terephthalate (PET) film, which was then compressed with a pre-fabricated isosceles trapezoidal silicon mold. A microlouver-patterned film was fabricated by curing the resin with $120 \mathrm{~W}$ UV irradiation and removing the mold. ${ }^{6-8)}$ Four oxides with high refractive indices, i.e., $\mathrm{ZnO}(n=2.00), \mathrm{ZrO}_{2}(n=2.15)$, $\mathrm{TiO}_{2}(n=2.34)$, and $\mathrm{CuO}(n=2.63)$, were selected as shadowing materials for microlouver filling. The nano-inks (Dittotechnology Co., Korea) had concentrations of $20 \mathrm{wt} \%$ and were composed of $10-20 \mathrm{~nm}$ nanoparticles. The nano-inks mixed with resin were applied onto the cured films using a bar coater. ${ }^{9)}$ After nano-ink filling, the films were dried at room temperature for two hours. To investigate the optical characteristics of the fabricated samples, luminance was measured according to viewing angle using a luminance meter (PR-655, Photo Research Inc., USA) and a fabricated angle mold. ${ }^{9)}$ An electro-luminescent light source with a high diffusivity was used, and the relative luminance was measured using the luminance meter in the angle range of $-80^{\circ}$ to $+80^{\circ}$ with respect to the front through the holes in the angle mold. The luminance measured in the system of this study includes the light intensity of various paths by the refraction or reflection in addition to transmission.

The relative luminance ratio $(\mathrm{RLR})$ at $30^{\circ}$ with respect to the front was defined as shown in equation (1):

$$
\text { RLR at } 30^{\circ}=\frac{L\left(-30^{\circ}\right)+L\left(+30^{\circ}\right)}{2 \times L\left(\text { front }, 0^{\circ}\right)}
$$

where $L\left(-30^{\circ}\right)$ is the luminance value at $-30^{\circ}, L\left(+30^{\circ}\right)$ is the luminance value at $+30^{\circ}$, and $L\left(\right.$ front, $0^{\circ}$ ) is the luminance value at the front.

The surfaces and cross-sectional shapes of the microlouver patterns were observed using a dual interference contrast microscope and a high-precision field emission scanning electron microscope (SEM) (ThermoFisher, Nova Nano SEM 450 , USA), respectively. In addition, the optical transmittance in the visible wavelength range was measured using a UVvisible spectrometer (Mega 800, Scinco Co., USA).

\section{Results and Discussion}

Figure 1(a) shows the light distribution images of the prepared films irradiated from the back side to the front and luminance distribution curves according to the direction predicted by the simulation software. The light distributions of the flat film without a pattern, the film with only an isosceles trapezoidal pattern, and films with various filled shadowing materials were compared. When the light distri- 
(a)

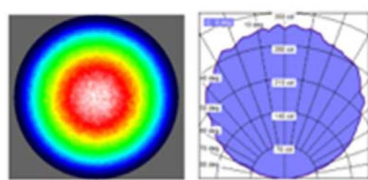

No pattern

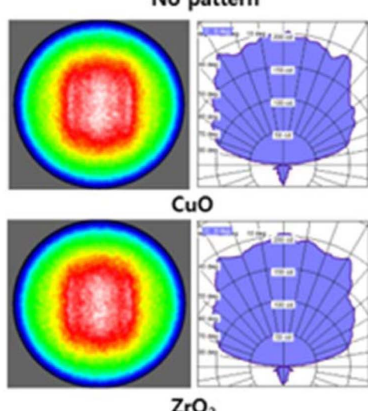

$\mathrm{ZrO}_{2}$

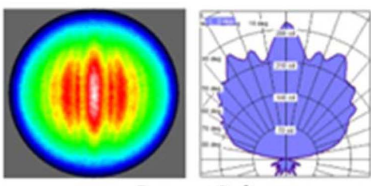

Pattern Only

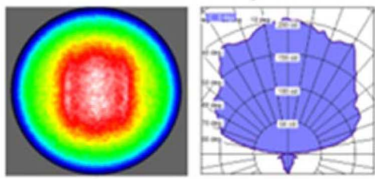

$\mathrm{TiO}_{2}$

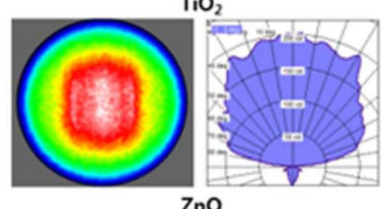

$\mathrm{ZnO}$

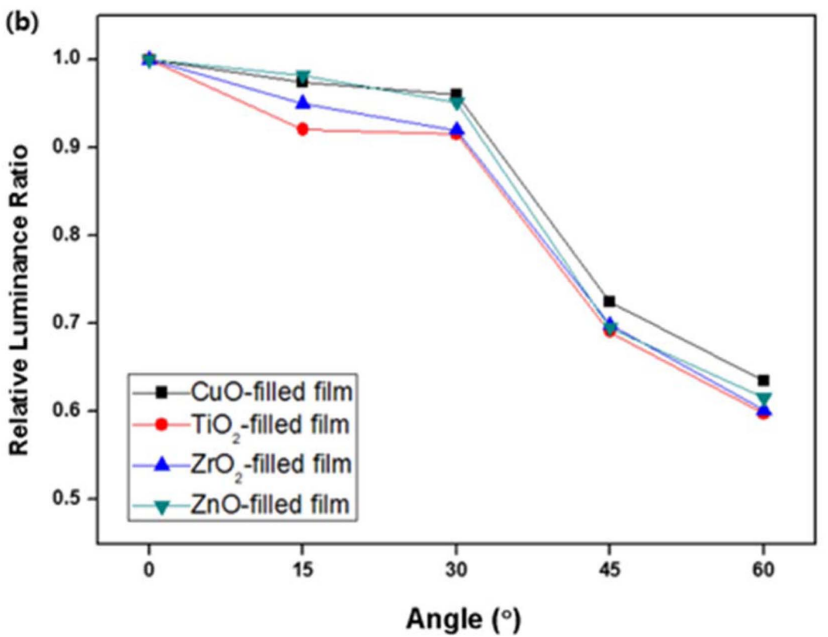

Fig. 1. Optical simulation results for the different shading materials: (a) light distribution curves and (b) relative luminance ratios according to measurement angle.

bution was circular in shape, as in the image of the film without a pattern, a clearly isotropic light distribution occurred according to viewing angle. For the film with a pattern but no filler, the light distribution was deformed compared with an isotropic distribution owing to light interference. When the patterns were filled with shadowing materials with high refractive indices $\left(\mathrm{CuO}, \mathrm{TiO}_{2}, \mathrm{ZrO}_{2}\right.$, and $\mathrm{ZnO}$ ), the light distribution images deviated from circularity, and optical visibility was limited in certain directions. Fig. 1(b) shows the calculated RLRs with respect to the front according to angle, which demonstrate the amount of transmitted light shown in Fig. 1(a). The films filled with shadowing materials exhibited similar RLR reduction tendencies with increasing viewing angle, and no significant differences were present depending on filling material. The RLR values were approximately 0.7 at $45^{\circ}$ with respect to the front and 0.6 at $60^{\circ}$.

Figure 2(a) shows planar optical microscope images of fabricated microlouver films with microlouver pattern spaces filled based on the simulation results with nano-inks using the bar coating method. The microlouver patterns were fab- (a)

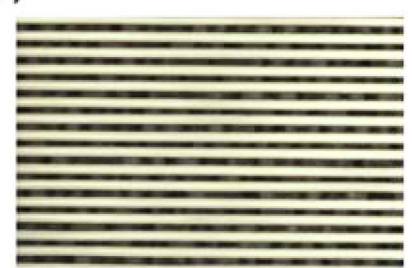

Zno

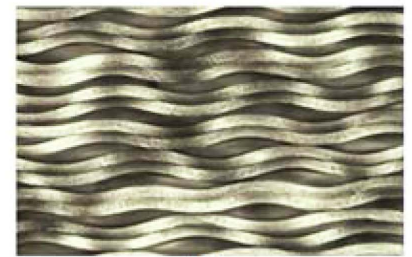

$\mathrm{ZrO}_{2}$

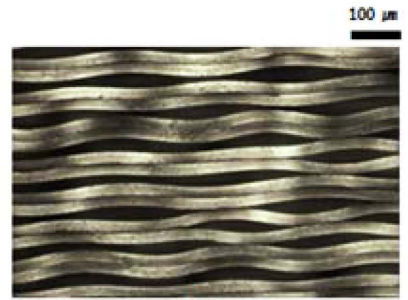

$\mathrm{TiO}_{2}$

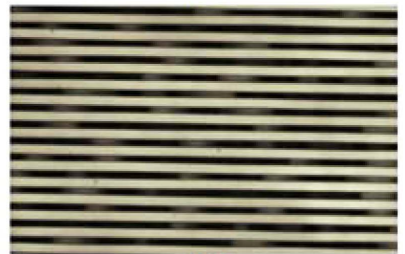

Cuo

(b)

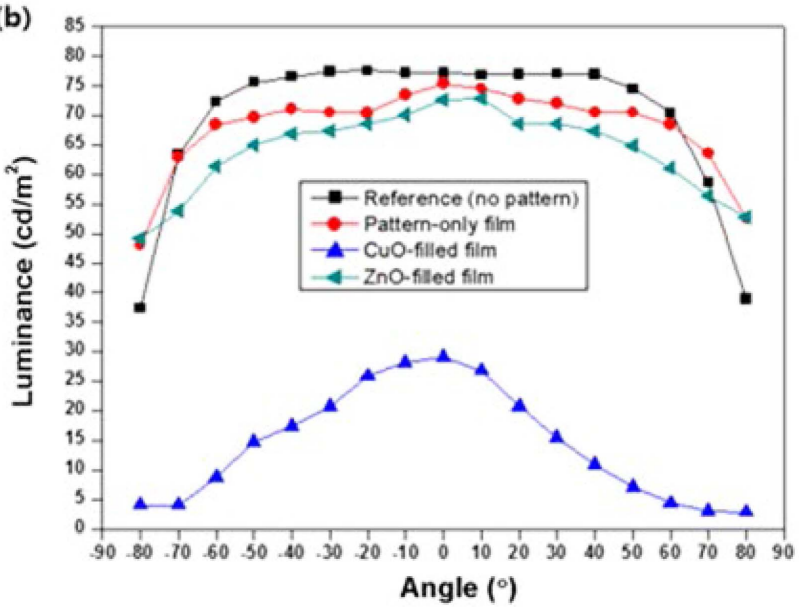

Fig. 2. (a) Optical planar images of microlouver films filled with various shading materials (b) Variation in luminance according to measurement angle for microlouver films filled with different shading materials.

ricated using nanoimprinting. The patterns were not distorted when $\mathrm{ZnO}$ and $\mathrm{CuO}$ nano-inks were applied but were distorted after the solvent dried when $\mathrm{ZrO}_{2}$ and $\mathrm{TiO}_{2}$ nanoinks were used. This is likely because $\mathrm{ZrO}_{2}$ and $\mathrm{TiO}_{2}$ had relatively high viscosity values of $4.65 \times 10^{-3} \mathrm{~Pa} \cdot \mathrm{s}$ and $5.04 \times$ $10^{-3} \mathrm{~Pa} \cdot \mathrm{s}$, respectively, and thus larger attractive forces caused by surface tension were applied to the resin pattern surfaces during the solvent drying process. ${ }^{10)}$ Fig. 2(b) shows the experimental luminance values according to viewing angle of the PET reference film with no pattern, the film with only a microlouver pattern, and the films filled with $\mathrm{CuO}$ and $\mathrm{ZnO}$ shading materials. For the films with no pattern and with only a microlouver pattern, RLRs with respect to the front were close to 1 for angles up to $60^{\circ}$, thus showing no information security characteristics. For the films with $\mathrm{ZnO}$ and $\mathrm{CuO}$ shading materials, however, the luminance significantly decreased for angles up to $60^{\circ}$. In the case of $\mathrm{CuO}$, however, the overall luminance was significantly reduced. This is likely because the $\mathrm{CuO}$ nano-ink had a very low optical transmittance; the film with a microlou- 
(a)

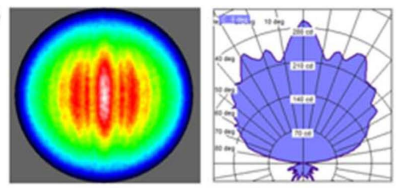

Pattern only

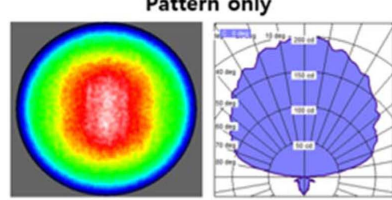

45- $\mu \mathrm{m} \mathrm{ZnO}$

(b)

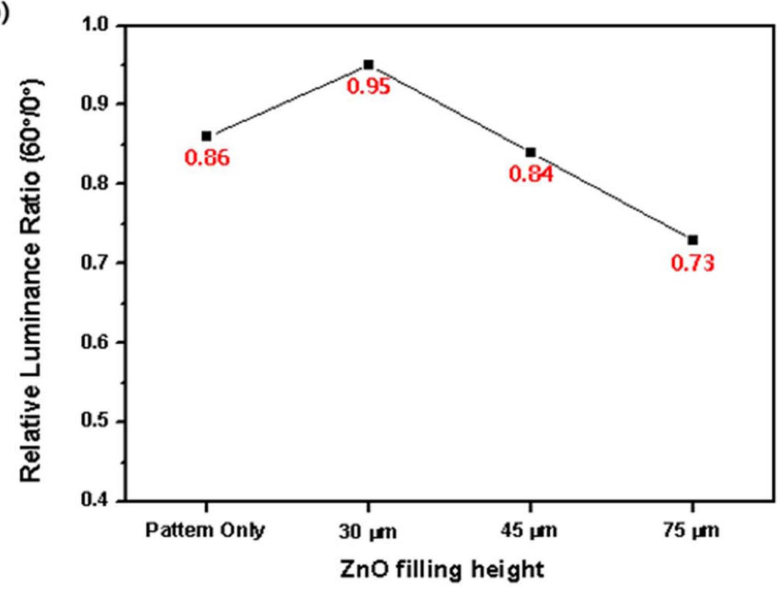

Fig. 3. Optical simulation results for different $\mathrm{ZnO}$ filling heights: (a) light distribution curves and (b) RLRs calculated at $60^{\circ}$ compared to the front $\left(0^{\circ}\right)$.

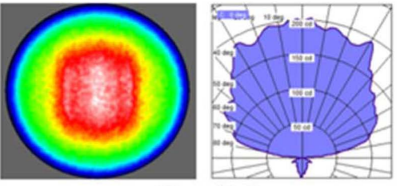

30- $\mu \mathrm{m} \mathrm{ZnO}$

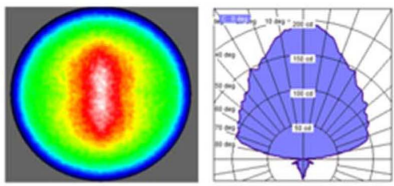

75- $\mu \mathrm{m} \mathrm{ZnO}$
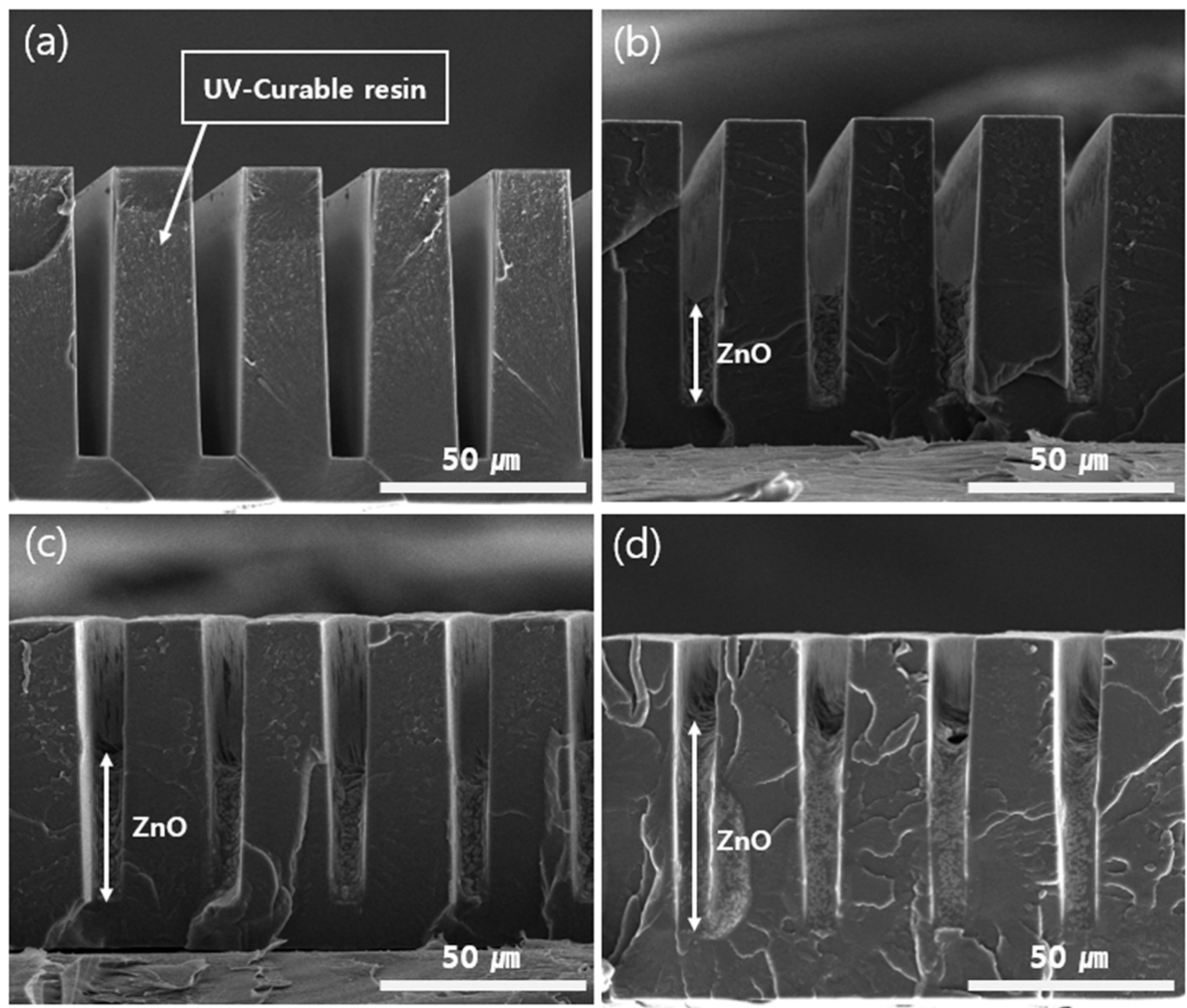

Fig. 4. Cross-sectional SEM images of microlouver films with different $\mathrm{ZnO}$ filling heights of (a) $0 \mu \mathrm{m}$, (b) $30 \mu \mathrm{m}$, (c) $45 \mu \mathrm{m}$, and (d) $75 \mu \mathrm{m}$.

ver pattern filled with $\mathrm{CuO}$ looked very dark even to the naked eye. As a result, the $\mathrm{ZnO}$ nano-ink, which had a relatively high optical transmittance and did not cause distortion of the microlouver pattern, was selected as a shading material candidate. In addition, to adjust the optical transmittance and information security characteristics of the microlouver film, the optical characteristics of the film were investigated according to $\mathrm{ZnO}$ filling height through simulation and experimental measurements.

Figure 3(a) shows the simulated light distribution images and luminance distribution curves according to angle for different $\mathrm{ZnO}$ filling heights with light irradiation from the back. When there was only a pattern on the film, interference occurred, and the light distribution image exhibited several overlapped ellipses. The luminance distribution curve depending on direction also had periodicity due to interference and exhibited a pointed maple-tree-leaf shape. When $\mathrm{ZnO}$ filling was used, the degree of interference decreased, and the light distribution images were not separated. In addition, the protruding parts in the luminance distribution curves significantly decreased. As the $\mathrm{ZnO}$ filling height increased, the light distribution images and distribution curves changed from a square-like shape to a circle and finally to a long triangular shape, indicating different optical characteristics depending on the angle. Fig. $3(\mathrm{~b})$ shows the RLRs calculated at $60^{\circ}$ according to $\mathrm{ZnO}$ filling height for the light sources in Fig. 3(a). For the patternonly film, the RLR at $60^{\circ}$ was 0.86 due to interference effects 

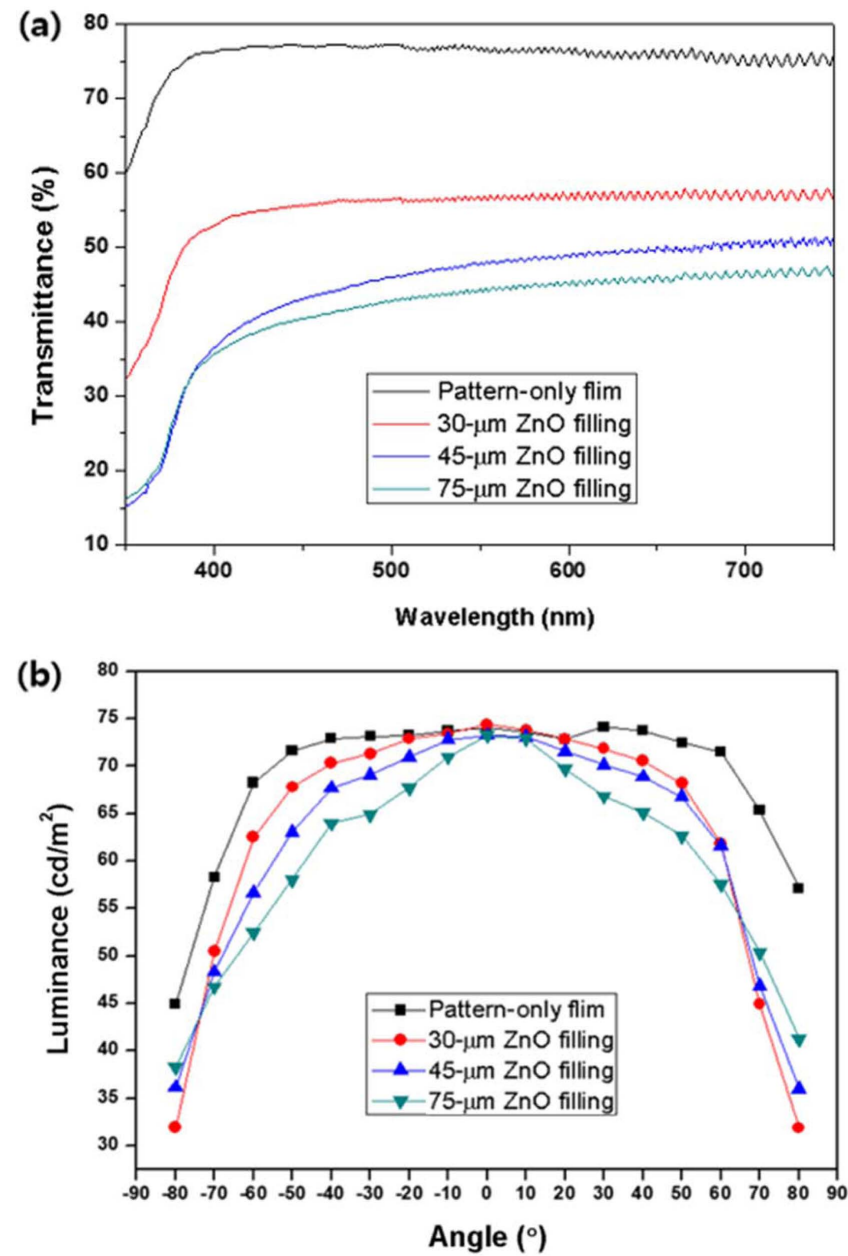

Fig. 5. (a) Transmittance of microlouver films with different $\mathrm{ZnO}$ filling heights in the visible light region. (b) Variation in the luminance according to measurement angle for various $\mathrm{ZnO}$ filling heights (films with pattern only and no $\mathrm{ZnO}$ filling were used for comparisons).

despite the lack of shading material. The RLR increased to 0.95 for the $\mathrm{ZnO}$ filling depth of $30 \mu \mathrm{m}$ but decreased to 0.73 for the filling depth of $75 \mu \mathrm{m}$; the films thus exhibited excellent security characteristics.

Figure 4 shows the cross-sectional SEM images of the information security films with the fabricated microlouver patterns and various $\mathrm{ZnO}$ filling heights. Silicon was processed and used as a stamp mold, and resin was fabricated with an isosceles trapezoidal microlouver pattern with a high aspect ratio using the UV nanoimprint process. The repeated geometry and dimensions of the patterns designed in the simulation were successfully transferred onto the PET films. The $\mathrm{ZnO}$ filling height increased depending on the number of bar coating repetitions of the resin with the nano-ink. Even when the $\mathrm{ZnO}$ filling process was repeated five times, the side walls of the microlouver patterns were hardly damaged. In the experiment, approximately $15 \mathrm{~mm}$ of the $\mathrm{ZnO}$ nano-ink was applied per coating. With repeated coatings, the cross-sectional images of the film patterns con-
Table 2. RLRs and Transmittances of Films with Different ZnO Filling Heights

\begin{tabular}{cccc}
\hline & $\begin{array}{c}\text { RLR } \\
\left(30^{\circ}\right)\end{array}$ & $\begin{array}{c}\text { RLR } \\
\left(60^{\circ}\right)\end{array}$ & $\begin{array}{c}\text { Transmittance } \\
(550 \mathrm{~nm})\end{array}$ \\
\hline Pattern-only film & 0.99 & 0.94 & $76.8 \%$ \\
$30-\mu \mathrm{m} \mathrm{ZnO}$ & 0.95 & 0.80 & $56.4 \%$ \\
$45-\mu \mathrm{m} \mathrm{ZnO}$ & 0.96 & 0.83 & $47.9 \%$ \\
$75-\mu \mathrm{m} \mathrm{ZnO}$ & 0.90 & 0.75 & $44.4 \%$ \\
\hline
\end{tabular}

firmed that the $\mathrm{ZnO}$ filling height increased. However, two, three, and five repetition coatings of $\mathrm{ZnO}$ filling exhibited heights of $31.5,44.5$, and $70.1 \mu \mathrm{m}$, respectively, with some processing errors.

Figure 5(a) shows the measured optical transmittances of the microlouver-patterned films shown in Fig. 4 in the visible wavelength range. The pattern-only film without $\mathrm{ZnO}$ filling exhibited a transmittance of $76.8 \%$ at a wavelength of $550 \mathrm{~nm}$. As the nano-ink filling was repeated, the transmittance value continuously decreased, reaching $44.4 \%$ for the film with a $\mathrm{ZnO}$ filling height of $75 \mu \mathrm{m}$. Fig. 5(b) shows the variation in luminance of the patterned films according to measurement angle measured by the system devised in this study. For the pattern-only film, the RLR
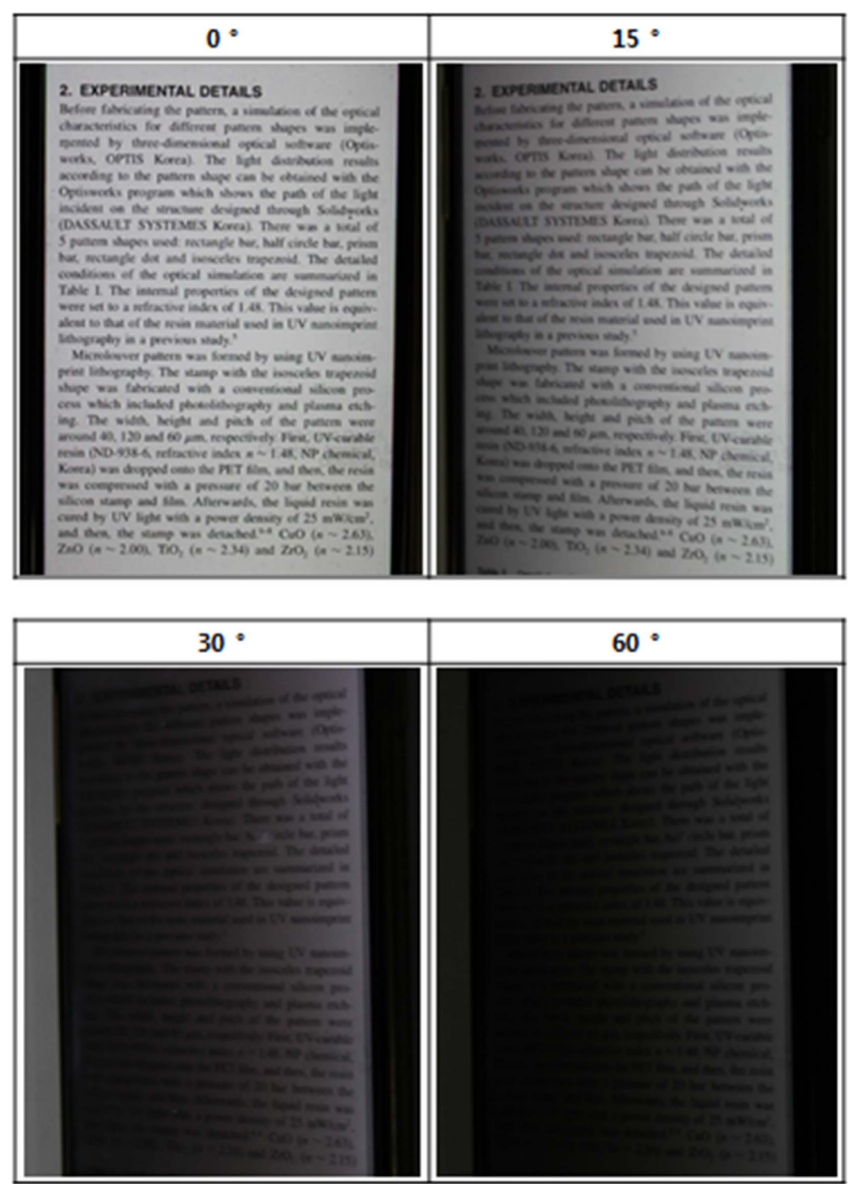

Fig. 6. Actual display images with the information security films at various viewing angles. 
value was close to 1 until the measurement angle reached $50^{\circ}$, indicating that the security effect was not significant. When $\mathrm{ZnO}$ was applied, however, the luminance sharply decreased compared to the front as filling height increased.

Table 2 shows the RLR values at $30^{\circ}$ and $60^{\circ}$ according to $\mathrm{ZnO}$ filling height measured in Fig. 5 and optical transmittances measured for a wavelength of $550 \mathrm{~nm}$. A comparison of the experimental RLR values measured at $60^{\circ}$ with the simulated values in Fig. 3(b) showed that the results were similar, especially for the films with $\mathrm{ZnO}$ filling heights of $45 \mu \mathrm{m}$ and $75 \mu \mathrm{m}$. For the film with a $\mathrm{ZnO}$ filling height of $75 \mu \mathrm{m}$, the RLR values measured at $30^{\circ}$ and $60^{\circ}$ were 0.9 and 0.75 , respectively, indicating excellent security characteristics.

Figure 6 shows the actual display images with the information security films at various viewing angles. The microlouver films with a $\mathrm{ZnO}$ filling height of $75 \mu \mathrm{m}$ were used. When the films fabricated in this study were placed on an actual display, the display screen was almost perfectly recognizable from both the front and $15^{\circ}$ side. However, accurate information acquisition was difficult at $30^{\circ}$ side due to significant darkness and no information was recognizable at $60^{\circ}$ due to severe display blackening.

\section{Conclusions}

Information security films capable of protecting personal information by reducing the viewing angle for a display screen were designed using optical simulation software. It was confirmed that the film structure, with high-refractiveindex shadowing materials applied to a certain height in the spaces between the high-aspect-ratio isosceles trapezoidal microlouver patterns, showed excellent information security characteristics. Information security films were fabricated based on the simulation results by applying the high-aspectratio isosceles trapezoidal pattern to a photosensitive PET resin film using a silicon mold in a UV nanoimprint process. For the shadowing material, $\mathrm{ZnO}$, which did not distort the microlouver pattern geometry in the nano-inking process and exhibited a relatively high optical transmittance, was determined as the most appropriate material. For the information security film with a $\mathrm{ZnO}$ filling height of $75 \mathrm{\mu m}$, the RLRs measured at $30^{\circ}$ and $60^{\circ}$ with respect to the front were 0.90 and 0.75 , respectively, indicating the film's excellent information security characteristics. The proposed method of fabricating microlouver pattern films using UV nanoimprinting and $\mathrm{ZnO}$ nano-ink filling is thus deemed to be a promising technology for fabricating information security films that control display viewing angles according to user position in terms of economic efficiency and process convenience.

\section{Acknowledgments}

This work was supported by the Priority Research Centers Program grant number NRF-2017R1A6A1A03015562 funded by the Ministry of Education (MOE) of the Republic of Korea.

\section{REFERENCES}

1. J. H. Kim, C. H. Lee, S. S. Lee, and K. C. Lee, "Highly Transparent Privacy Filter Film with Image Distortion," Opt. Express, 22 [24] 29799-804 (2014).

2. H. S. Yoon, S. G. Oh, D. S. Kang, J. M. Park, S. J. Choi, K. Y. Suh, K. H. Char, and H. H. Lee, "Arrays of Lucius Microprisms for Directional Allocation of Light and Autostereoscopic Three-Dimensional Displays," Nat. Commun., 2 455 (2011)

3. M. B. Chan-Park, J. Zhang, Y. Yan, and C. Y. Yue, "Fabrication of Large SU-8 Mold with High Aspect Ratio Microchannels by UV Exposure Dose Reduction," Sens. Actuators, $B, 101$ [1-2] 175-82 (2004).

4. J. B. Lee, K. H. Choi, and K. K. Yoo, "Innovative SU-8 Lithography Techniques and Their Applications," Micromachines, 6 [1] 1-18 (2015).

5. Y. Hirai, S. Yoshida, N. Takagi, Y. Tanaka, H. Yabe, K. Sasaki, H. Sumitani, and K. Yamamoto, "High Aspect Pattern Fabrication by Nano Imprint Lithography Using Fine Diamond Mold," Jpn. J. Appl. Phys., 423863 (2003).

6. S. Y. Lee, S. E. Lee, H. C. Lee, H. N. Lee, and H. J. Kim, "Improvement in the Optical and Electrical Properties of Ga-doped Zinc-Oxide Films by Using Nano-Imprinted Pattern Arrays and Post-Annealing," J. Korean Phys. Soc., 66 246-51 (2015).

7. T. W. Lin, C. F. Chen, J. J. Yang, and Y. S. Liao, "A DualDirectional Light-Control Film with a High-Sag and High-Asymmetrical-Shape Microlens Array Fabricated by a UV Imprinting Process,” J. Micromech. Microeng., 18 [9] 095029-38 (2008).

8. B. D. Gates, "Nanofabrication with Molds \& Stamps," Mater. Today, 8 [2] 44-9 (2005).

9. S. W. Kim, S. E. Lee, C. B. Yoon, H. Lee, and H. C. Lee, "Development of Anti-Spy Privacy Films with Controlled Viewing Angle by Using UV Nanoimprint Lithography and Nanoink Filling," Nanosci. Nanotechnol. Lett., 10 [8] 1147-51 (2018)

10. G. H. Kim, S. H. Cho, J. H. Han, Y. B. Lee, C. H. Roh, K. Hong, and S. K. Park, "Effect of Drying Liquid on Stiction of High Aspect Ratio Structures," Solid State Phenom., 187 75-8 (2012). 